\title{
Polysaccharide isolated from Korean-style soy sauce activates macrophages via the MAPK and NK-kB pathways
}

\author{
Kwang-Soon SHIN ${ }^{1}$, Haesun SEO ${ }^{2}$, Sue Jung LEE$^{1}$, Sooyun SUNG ${ }^{2}$, Dahyun HWANG ${ }^{2,3 *}$ (D)
}

\begin{abstract}
Soy sauce is a staple fermented food in Korea, however, there are relatively limited studies on soy sauce in Korea compared to that in Japan. In this study, the immuno-stimulating activities are compared in polysaccharides isolated from soy sauce in Korea and Japan. Crude polysaccharides was isolated, and which were named as Korean-style soy sauce (KSS-0) and Japanese-style soy sauce (JSS-0). Then, difference in cytokine production was compared in peritoneal macrophages, and KSS-0 showed higher cytokine production than JSS-0. The KSS-0 was purified into two polysaccharides, which were named as KSS-I and KSS-II. The polysaccharides consisted mainly galacturonic acid, xylose, and galactose. Out of the four polysaccharides isolated, KSSII enhanced NO and cytokines production the most. Western blot analysis showed that KSS-II phosphorylated the MAPKs and nuclear factor NF- $\mathrm{kB}$ in RAW 264.7 cells in a dose-dependent manner. These results suggested that KSS-II activates macrophages via the MAPK and NF- $\kappa B$ pathways, and also induces an increase in the cytokine production. In conclusion, the polysaccharides isolated from Korean soy sauce have better immune-stimulating activities than those from Japan and may be used as potential functional foods.
\end{abstract}

Keywords: soy sauce; polysaccharide; macrophage; cytokines; functional food.

Practical Application: Soy sauce is a representative food in Korea. However, the biological activities have not been explored extensively, and the mechanism has also not been identified. Food has no side effects, so food and its ingredients are recognized as substitutes for medicine. In this study, polysaccharides are isolated from soy sauce in Korea and Japan, and immune stimulating activities are compared. The monosaccharide composition and signaling pathway were also analyzed in detail. Our data showed that polysaccharide in Korean-style soy sauce showed good immune enhancing effect, and this polysaccharide might be used as functional foods.

\section{Introduction}

Soy sauce is one of the best known soy products worldwide, although its production methodology varies significantly depending on the country. Due to the variability in raw materials, fermentation methods, and microbial differentiation, diverse types of soy sauce are produced and used. In Korea, soy sauce is a staple fermented food and the most used ingredient in Korean cooking. However, studies on Korean soy sauce are relatively scarce compared to its Japanese counterpart. The immunological functions of Japanese soy sauce, such as anti-allergic activity (Kobayashi, 2005) and enhancement of intestinal immunity (Matsushita et al., 2008) have been reported. Soybean is the sole raw ingredient for Korean soy sauce, while Japanese soy sauce is made using a blend of soybeans and wheat flour. Therefore, the physiological activities of Korean and Japanese soy sauces are expected to be different.

Previously, polysaccharides have been reported as energy sources for the body. Recently, polysaccharide research has risen in importance as novel features of polysaccharides have been discovered. Polysaccharides have no side effects and possess immunity boosting effects; therefore, they are recognized as substitutes for medicines (Tzianabos, 2000). They have been shown to exhibit diverse biological activities, including anti-carcinogenic, anti-coagulant, immuno-stimulant, and anti-oxidant activities (Wang et al., 2013). In our previous study, we demonstrated the biological activities of plant-derived polysaccharides, including stimulatory activity on innate immune cells (Kim et al., 2016; Park et al., 2012). Of the multiple activities displayed by polysaccharides, we focused their immune-stimulating effect on macrophages.

Macrophages are key immune cells that provide protection against infection and cancer. They regulate both innate and adaptive immune systems (Yoon et al., 2003). When macrophages are activated, they produce various immune mediators such as cytokines, nitric oxide (NO), hydrogen peroxide, and prostaglandins. NO participates in regulating various immune responses (Wang et al., 2009). Interleukin-6 (IL-6) and tumor necrosis factor- $\alpha$ (TNF- $\alpha$ ) secrete chemokines or adhesion molecules serially, and recruit diverse immune cells to the 
infection sites (Lee et al., 2010). IL-12 plays an important role in cell-mediated immunity by activating $\mathrm{T}$ and natural killer cells against intracellular infection (Xing et al., 2000). In a previous study on signaling pathway, it was observed that plant-derived polysaccharides usually recognize and bind to pattern recognition receptors on the surface of macrophages and activate them. These polysaccharides in turn activate intracellular signaling pathways, including mitogen-activated protein kinases (MAPK) and nuclear factor kappa-light-chain-enhancer of activated $\mathrm{B}$ cells $(\mathrm{NK}-\kappa \mathrm{B})$ pathways, leading to regulation of the immune system via secretion of cytokines, enzymes (iNOS and COX-2), and chemokines (Kim et al., 2019).

In this present study, we isolated and purified polysaccharides from different types of soy sauce and analyzed their chemical properties. We investigated their macrophage-stimulating activities by evaluating the production of $\mathrm{NO}$ and cytokines in peritoneal macrophages, and further, showed the activation of signaling pathways using RAW 264.7 cells.

\section{Materials and methods}

\subsection{Materials}

Japanese soy sauce was purchased from a Japanese manufacturer ' $\mathrm{K}$ ' and the Korean soy sauce was bought from the Korean traditional food manufacturer, 'L' (Sunchang, Jeollabuk-do, Korea). Sephadex G-75 gel permeation chromatography medium was purchased from GE Healthcare Life Sciences (Uppsala, Sweden), and dialysis tubing (Spectra/ Por2 dialysis membrane, $12-14 \mathrm{kDa}$ molecular weight cutoff) was obtained from Spectrum Laboratories Inc. (Rancho Dominguez, CA, USA). The pullulan standards for analyzing the molecular weights of the polysaccharides were obtained from Showa Denko (Tokyo, Japan). Dulbecco's modified Eagle's medium (DMEM) and hybridoma-SFM was purchased from Gibco BRL Co. (Grand Island, NY, USA), and fetal bovine serum (FBS) was purchased from Welgene Inc. (Gyeongsan, Korea). Mouse IL-6 and IL-12 ELISA kits were purchased from BD Bioscience (San Diego, CA, USA), TNF- $a$ ELISA was purchased from eBioscience (San Diego, CA, USA); and Escherichia coli lipopolysaccharides (LPS), thioglycolate (TG) was purchased from Sigma (St. Louis, MO, USA). Antibodies against JNK (FL), ERK (C-16), p38 (C-20), IкBa (C-21), p65 (C-20) and $\beta$-actin (I-19) were purchased from Santa Cruz Biotechnologies (Santa Cruz, CA, USA). Phospho(p)-JNK (Thr-183/Tyr-185), p-ERK (Thr-202/Tyr-204), p-p38 (Thr180/Tyr-182), p-p65 (Ser-536), p-c-Jun (Ser-73), c-Jun (60A8) antibodies were purchased from Cell Signaling Technology (Denver, MA, USA).

\subsection{Isolation and purification of polysaccharides from soy sauce}

Korean and Japanese soy sauce were dissolved overnight by adding approximately four-fold ethanol up to $80 \%$ of the total concentration. After the supernatant was separated by centrifugation $(6,000 \mathrm{rpm}, 30 \mathrm{~min})$, it was precipitated with thrice the volume of ethanol and dialyzed for two days using dialysis tubes. The solution was finally lyophilized to yield crude polysaccharides named as JSS- 0 and KSS- 0 . To further purify KSS-0, it was applied to an open $(4 \mathrm{~cm} \times 95 \mathrm{~cm})$ Sephadex G-75 column, equilibrated with $50 \mathrm{mM}$ ammonium formate buffer ( $\mathrm{pH}$ 5.5), and eluted with the same buffer. Two major purified polysaccharides (KSS-I and KSS-II) were obtained and lyophilized after desalting by dialysis (Figure 1 and Figure 2A).

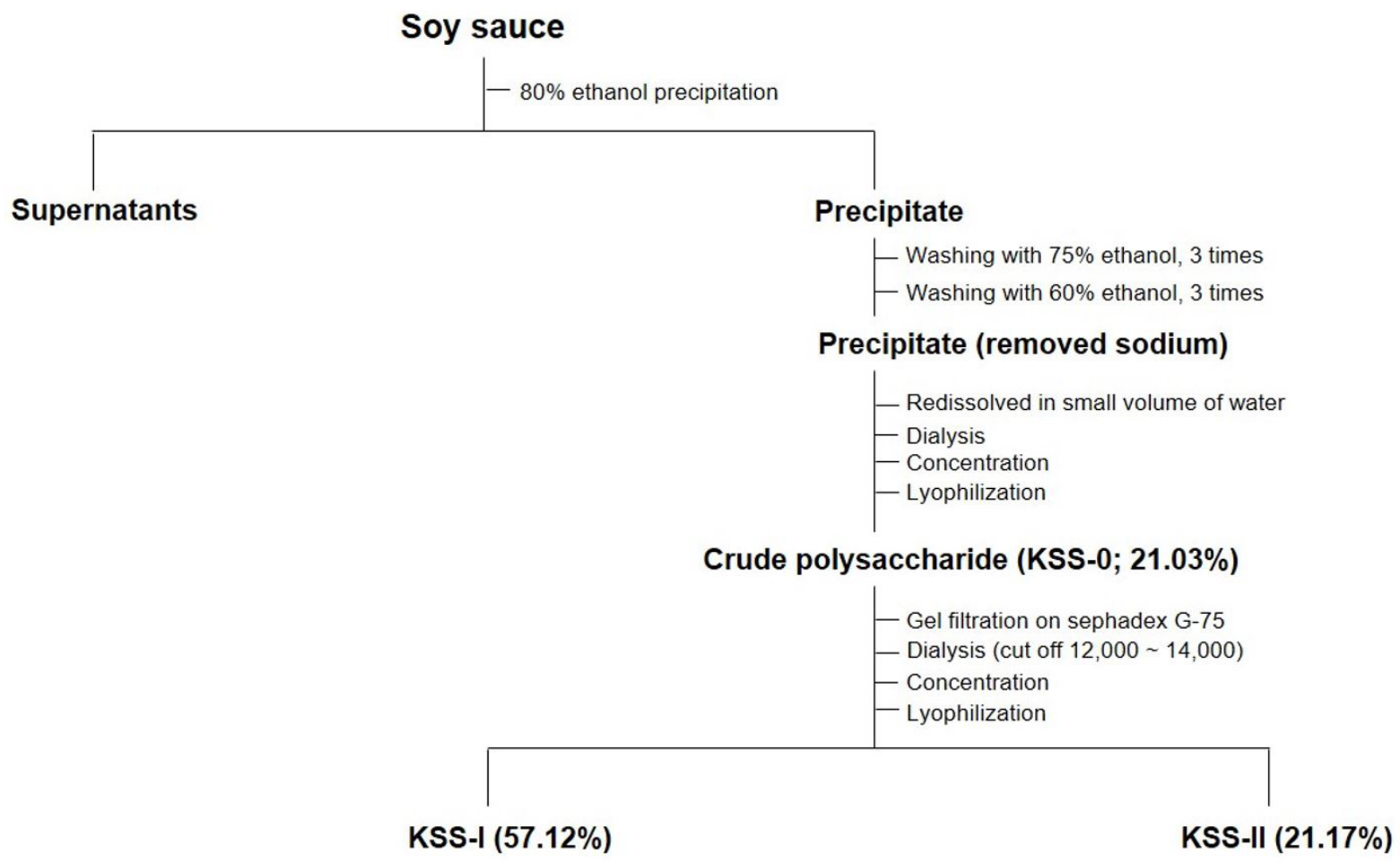

Figure 1. Schematic of the isolation and purification protocol for the polysaccharides from Korean soy sauce. 


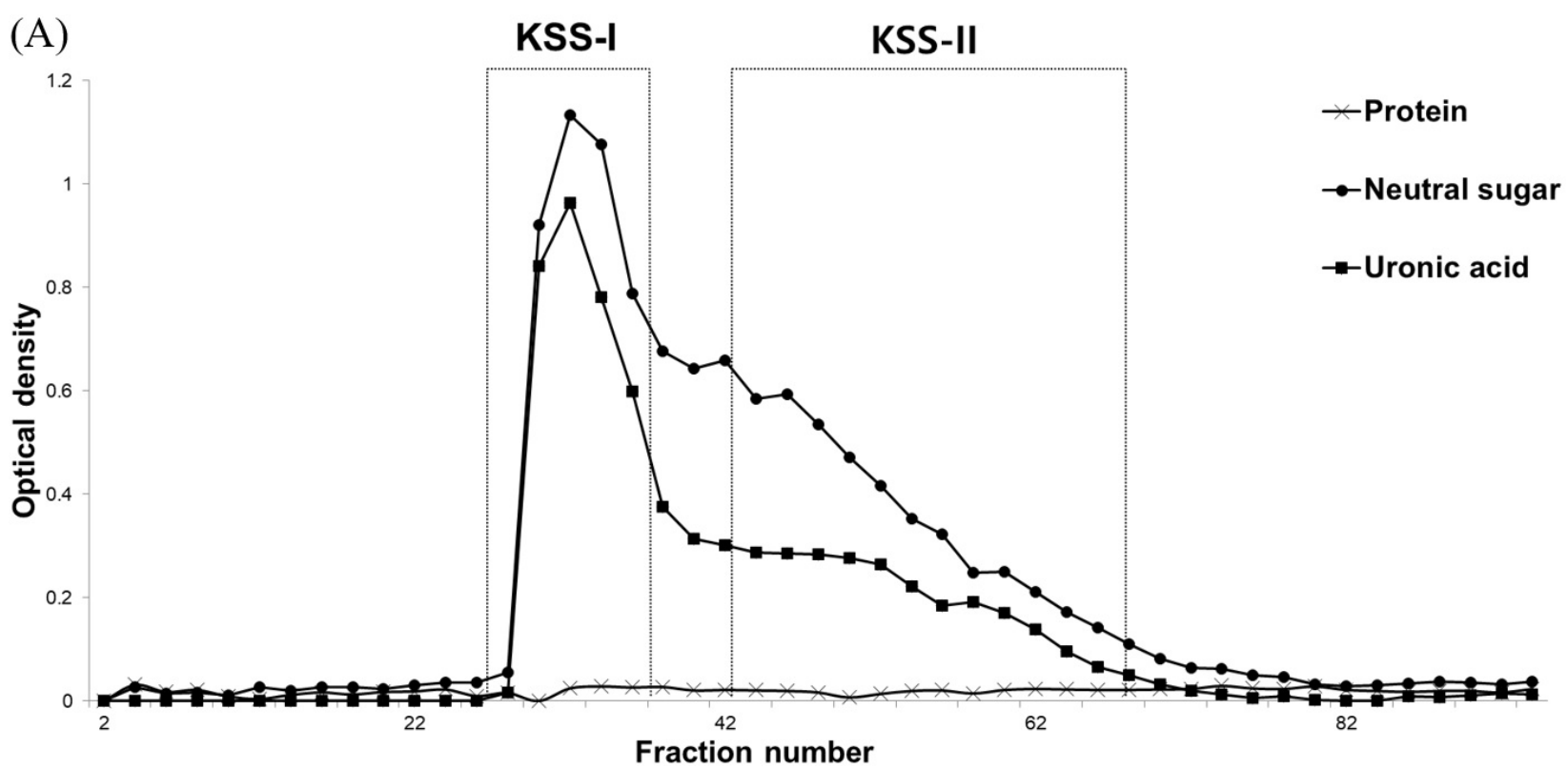

(B)
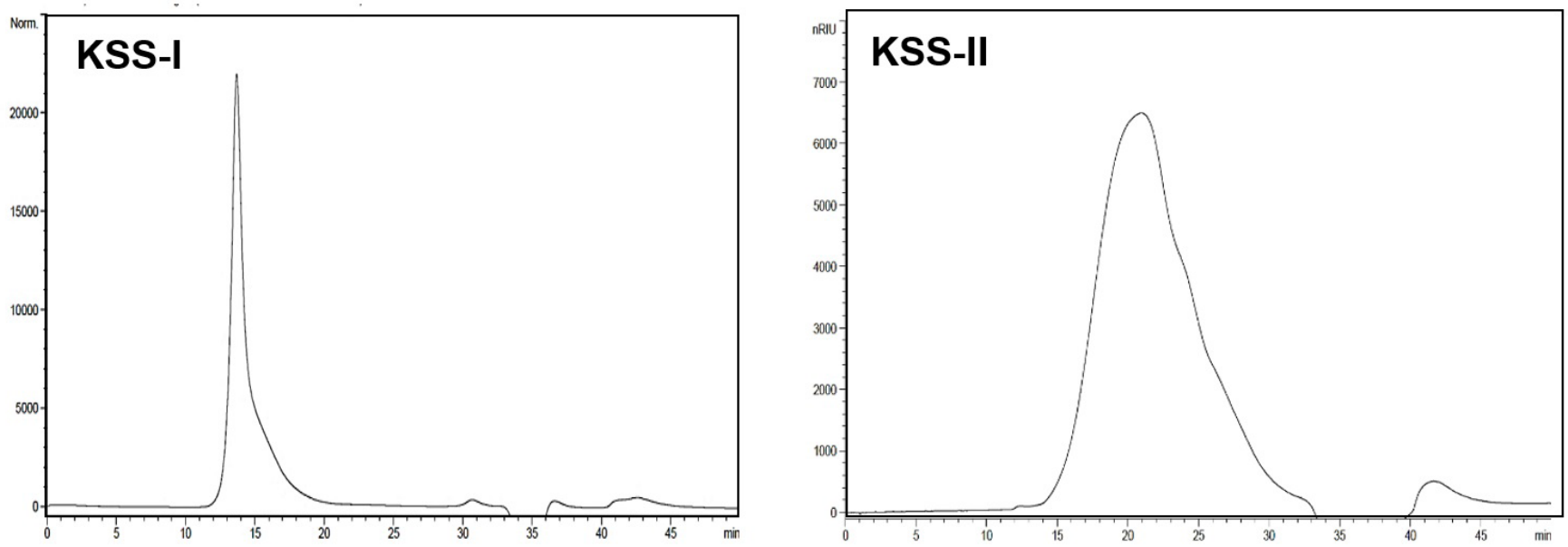

Figure 2. Purification of the polysaccharides. (A) Elution profile of the purified polysaccharide fractions and (B) their high-performance size exclusion chromatograms. The crude polysaccharide was purified using Sephadex G-75 column $(4 \times 95)$.

\subsection{Analysis of monosaccharide composition}

The neutral sugar and uronic acid contents were measured by following the phenol-sulfuric acid method (DuBois et al., 1956) and m-hydroxybiphenyl method (Blumenkrantz \& Asboe-Hansen, 1973), respectively. The protein content was quantified using the Bradford method. The aldose component was analyzed as alditol acetate. To measure the uronic acid content, the reduced hydrolysates were loaded onto the Dowex- 1 resin and the bonded aldonic acids were eluted using $1 \mathrm{~N} \mathrm{HCl}$. Then, the fraction was evaporated at $40^{\circ} \mathrm{C}$ in a stream of filtered air. The resulting lactones were reduced under neutral conditions (Jones \& Albersheim, 1972). After acetylation, the resulting carboxyl-reduced alditol acetates were analyzed using gas liquid chromatography (GLC) (Zhao et al., 1991). GLC was performed using an HL-6890 Series II gas chromatograph (Hewlett-Packard, Palo Alto, CA, USA) equipped with a flame ionization detector (FID) using a Supelco
SP-2380 capillary column $(30 \mathrm{~m} \times 0.25 \mathrm{~mm}$ i.d., $0.2 \mu \mathrm{m}$ film, Bellefonte, PA, USA).

\subsection{Cell culture and evaluation of cell proliferation using murine peritoneal macrophages}

Peritoneal macrophages were obtained from 5\% (w/v) TGtreated BALB/c mice as described previously (Park et al., 2017). RAW 264.7 cells were purchased from the Korean Cell Line Bank (Seoul, Korea). Peritoneal macrophages and RAW 264.7 cells were cultured in DMEM supplemented with 10\% FBS and 1\% penicillin-streptomycin $(\mathrm{P} / \mathrm{S})$ at $37^{\circ} \mathrm{C}$ in a humidified incubator with $5 \% \mathrm{CO}_{2}$. To evaluate the effect of polysaccharides on cell proliferation, peritoneal macrophages $\left(2.5 \times 10^{5}\right.$ cells/well in DMEM-10\% FBS) were dispensed into each well of a 96-well culture plate overnight. The culture medium was removed and 
$100 \mu \mathrm{L}$ of 1:10 diluted WST-based reagent EZ-cyTox (Daeil Lab Service, Seoul, Korea) was added into the cell culture medium. Then, the cells were incubated for $1 \mathrm{~h}$ at room temperature. Absorbance was measured at $450 \mathrm{~nm}$ using a microplate reader (Molecular Device, Sunnyvale, CA, USA). Cell viability was expressed in terms of relative percentage of live treated cells to the untreated negative control cells.

\subsection{Detection of NO levels and pro-inflammatory production in murine peritoneal macrophages}

Peritoneal macrophages $\left(2.5 \times 10^{5}\right.$ cells/well in DMEM-10\% FBS) were dispensed into each well of a 96-well culture plate. After incubation for $1 \mathrm{~h}$, the polysaccharides were added to the wells and incubated for $24 \mathrm{~h}$ in a $5 \% \mathrm{CO}_{2}$ incubator at $37^{\circ} \mathrm{C}$. The cell supernatants were analyzed to detect $\mathrm{NO}$ and various cytokines (IL-6, IL-12, and TNF- $\alpha$ ) using ELISA kits according to the manufacturer's protocol.

\subsection{Western blot analysis}

RAW 264.7 cells $\left(2.5 \times 10^{6}\right.$ cells/well in DMEM-10\% FBS) were treated with the indicated concentration of KSSII for $30 \mathrm{~min}$. The cells were washed with PBS and lysed to extract the proteins using Pro-Prep protein extraction solution (Intron, Seoul, Korea). Protein concentration was determined using Bradford assay. Equal amount $(30 \mu \mathrm{g})$ of protein from each sample was loaded in $10 \%$ sodium dodecyl sulfate-polyacrylamide gel. Protein electrophoresis, transfer, and membrane development were all performed as described in our previous report (Shin et al., 2018).

\subsection{Statistical analysis}

All statistical analyses were performed using SPSS version 12.0 for Windows (SPSS, Chicago, IL, USA). Values were expressed as mean \pm standard deviation (SD) of three independent experiments, performed in triplicate. $p<0.05$ was considered as statistically significant (Student's $t$-test). Statistical differences among groups were evaluated using analysis of variance, followed by Duncan's multiple range tests.

\section{Results and discussion}

\subsection{Chemical characterization of the four polysaccharides}

Nowadays, diverse physiological activities of polysaccharide have been reported. Polysaccharides are usually extracted from plants, and many plant-derived polysaccharides have non- or less toxicity and few side effects (Nie et al., 2019). For these reasons, the ability of polysaccharide as functional food is being reevaluated.

The soy sauce is one of the plant-derived food and include free amino acids, 5'-nucleotides, small peptides, soluble saccharides, and polyols (Kong et al., 2018). The composition of soy sauce varies by raw materials, fermentation methods, and microbial differentiation (Diez-Simon et al., 2020). The monosaccharide composition, molecular size, presence of glucosidal bonds, and branching patterns of polysaccharides are known to influence their biological activity (Zhang et al., 2014; Chandarajoti et al., 2014; Liu et al., 2014). We measured the monosaccharide composition and molecular size of polysaccharides for investigating chemical characterization. We found that all four polysaccharide fractions consisted of neutral sugar (56 62\%), uronic acid (30 35\%), and a small amount of proteins and polyphenols. There were minor differences in the chemical composition. On the other hand, there were some differences in sugar composition. JSS-0 consisted mainly of galacturonic acid (30.64\%), galactose $(23.32 \%)$, and xylose $(12.79 \%)$. The major constituents of KSS-0 were galacturonic acid (33.51\%), xylose (16.96\%), and galactose $(14.97 \%)$. our results showed that galacturonic acid was main ingredient in both JSS-0 and KSS-0. Usually, arabinose and galactose are main ingredients in soy sauce (Jia et al., 2015). This result was estimated that other materials were added during fermentation. Also, KSS-II was the most active fraction in immune-stimulation, however, the sugar composition are similar. After purification of KSS-0 into KSS-I and KSS-II, the amount of xylose and galactose increased by approximately $4 \%$ and $2 \%$, respectively (Table 1 ). This requires further study to identify the active ingredient.

Table 1. Chemical properties of four polysaccharides.

\begin{tabular}{|c|c|c|c|c|}
\hline Chemical Composition (\%) & JSS-0 & KSS-0 & KSS-I & KSS-II \\
\hline Neutral sugar & $60.56 \pm 1.87$ & $56.47 \pm 1.11$ & $61.25 \pm 3.36$ & $58.58 \pm 0.54$ \\
\hline Uronic acid & $31.8 \pm 0.76$ & $34.89 \pm 1.23$ & $33.78 \pm 0.38$ & $34.6 \pm 0.43$ \\
\hline Protein & $1.48 \pm 0.19$ & $1.93 \pm 0.41$ & $2.74 \pm 0.53$ & $4.28 \pm 0.32$ \\
\hline Polyphenol & $5.34 \pm 0.09$ & $5.45 \pm 0.09$ & $2.23 \pm 0.22$ & $2.54 \pm 0.55$ \\
\hline \multicolumn{5}{|c|}{ Component Sugar (Mole \%) } \\
\hline Rhamnose & $7.33 \pm 0.1$ & $4.36 \pm 0.1$ & $5.32 \pm 0.0$ & $3.35 \pm 0.0$ \\
\hline Fucose & $5.36 \pm 0.1$ & $7.11 \pm 0.1$ & $9.25 \pm 0.2$ & $7.61 \pm 0.1$ \\
\hline Arabinose & $2.82 \pm 0.2$ & $2.65 \pm 0.1$ & $2.13 \pm 0.0$ & $3.35 \pm 0.1$ \\
\hline Xylose & $12.79 \pm 0.1$ & $16.96 \pm 0.1$ & $20.42 \pm 0.5$ & $19.59 \pm 0.2$ \\
\hline Mannose & $7.81 \pm 0.0$ & $7.58 \pm 0.1$ & $5.64 \pm 0.1$ & $6.8 \pm 0.2$ \\
\hline Galactose & $23.32 \pm 0.1$ & $14.97 \pm 0.2$ & $14.46 \pm 0.0$ & $16.14 \pm 0.3$ \\
\hline Glucose & $1.13 \pm 0.1$ & $2.84 \pm 0.0$ & $4.04 \pm 0.0$ & $1.73 \pm 0.0$ \\
\hline Glucuronic acid & $1.16 \pm 0.1$ & $1.38 \pm 0.1$ & $0.89 \pm 0.1$ & $1.47 \pm 0.2$ \\
\hline Galacturonic acid & $30.64 \pm 0.7$ & $33.51 \pm 0.0$ & $32.89 \pm 0.8$ & $33.13 \pm 1.0$ \\
\hline
\end{tabular}


The molecular weight of KSS-I was calculated to be over 80 $\mathrm{kDa}$ (Figure 2B). Based on the broad HPLC peak, we determined that KSS-II consisted of mainly low molecular weight constituents (Figure 2B).

\subsection{Effect of all four polysaccharides on the cell viability of murine peritoneal macrophages}

Among diverse physiological activities, we measured macrophage-stimulating activity. Macrophage are the body's first line of defense and have many roles, so they directly affect the human body. To determine the appropriate dose range for treating the macrophages with the four polysaccharides, we measured their cytotoxicity. If cell viability was more that $80 \%$ compared to normal control, it was judged to be non-toxic. We observed that all of the polysaccharides did not show cytotoxicity toward macrophages at concentrations ranging from $1 \sim 1000 \mu \mathrm{g} / \mathrm{mL}$ (Figure 3). Moreover, $1000 \mu \mathrm{g} / \mathrm{mL}$ of KSS-II significantly increased macrophage proliferation by approximately $8 \%$. It means that the KSS-II is effective for immune cell proliferation.

\subsection{Effect of the four polysaccharides on cytokines and NO production in murine peritoneal macrophages}

We chose NO and three cytokines (IL-6, IL-12, and TNF- $\alpha$ ) as the macrophage-stimulating mediators. $\mathrm{NO}$ is known to be a key mediator of nonspecific immunity, and is produced by activated macrophages when cells are infected by bacteria, viruses, and parasites (Billack, 2006). When macrophages are activated by plant-derived polysaccharides, they usually release cytokines such as IL-6, IL-12, and TNF- $\alpha$ (Aderem \& Underhill, 1999). Therefore, we chose to investigate NO and three cytokines.

We found that, roughly, the production of both cytokines as well as NO was highest in the following order: KSS-II > KSS-I> KSS-0 > JSS-0. In particular, $1000 \mu \mathrm{g} / \mathrm{mL}$ of KSS-II significantly increased NO and IL-6 production by approximately 1.76fold and 1.24-fold compared to LPS-treated positive control (Figure 4A, 4D). The other polysaccharide concentrations also showed higher production than NC (Figure 4A-D). As a result, KSS-II was the most effective for all measurements and it is estimated that KSS-II has an active ingredient.

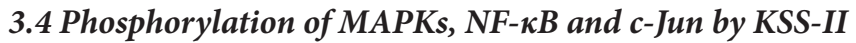 in RAW 264.7 cells}

To investigating the signaling pathway by KSS-II, we searched two main pathway (MAPKs and NF- $\kappa \mathrm{B}$ ) of macrophage and did western blot analysis. MAPKs and NF- $\kappa \mathrm{B}$ pathways are the representative signaling pathways for activated macrophages (Yang et al., 2019). MAPK pathways are mediated by ERK, JNK, and p38 protein kinase, and these enzymes are regulated via phosphorylation (Johnson \& Lapadat, 2002). ERK is involved in cell division, JNK is known as a critical regulator of transcription, and p38 is a major player during inflammatory responses (Johnson \& Lapadat, 2002; Yang et al., 2014). NF- $\kappa B$ is another major immune-stimulating factor, which is primarily

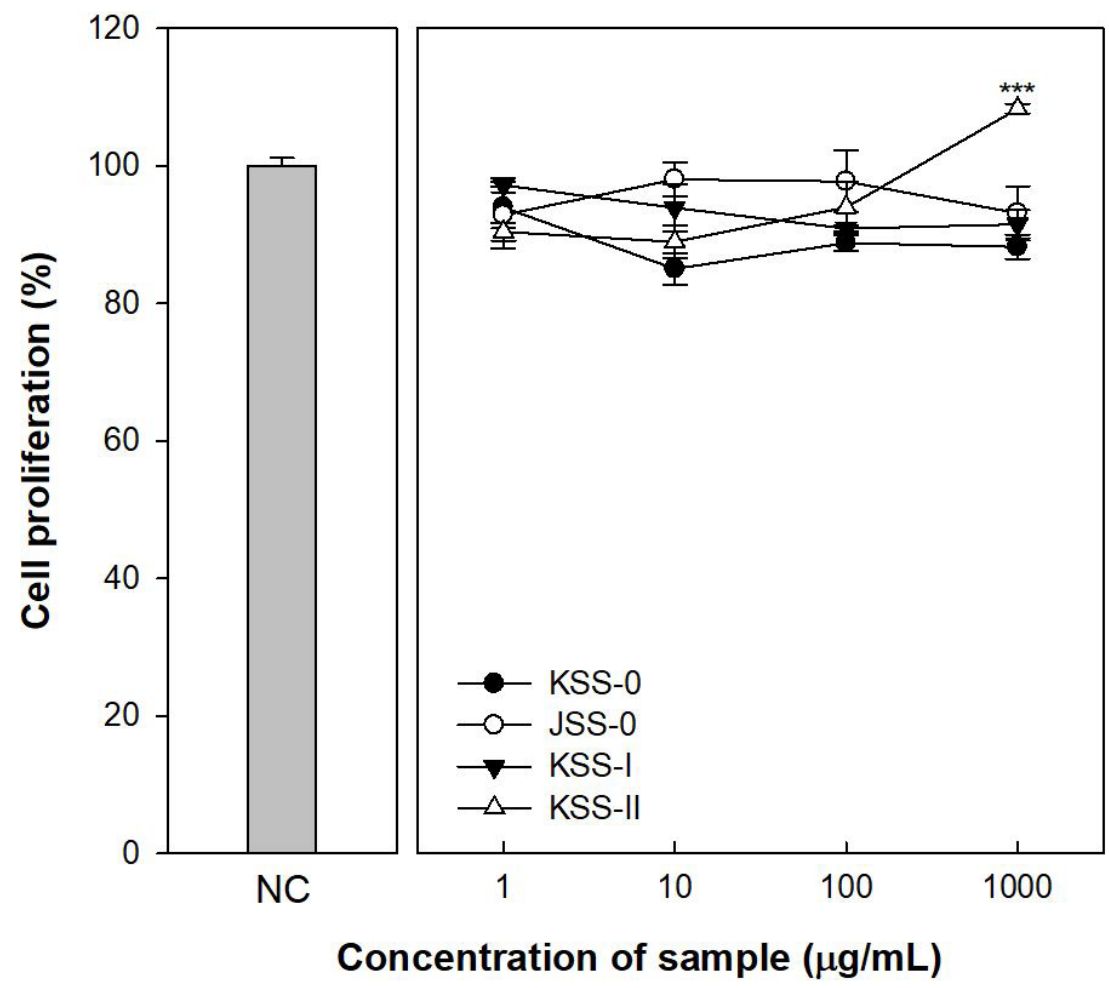

Figure 3. Effect of the four polysaccharides on cell viability of peritoneal macrophages. Peritoneal macrophages $\left(2.5 \times 10^{5} \mathrm{cells} / \mathrm{mL}\right)$ were treated with polysaccharides for $24 \mathrm{~h}$. NC means negative control treated with media only. Data was presented as the mean \pm SD of three independent experiments. Different superscripts were significantly different between the negative control and respective sample by Student's T-test. ${ }^{* * *} p<0.001$. 
composed of the protein p50 and p65 and exists in the latent form in the cytosol as a dimer complex bound to the inhibitor protein, $\mathrm{I} \kappa \mathrm{B}$. When NF- $\kappa \mathrm{B}$ is activated by stimuli, I $\mathrm{B}$ is degraded and NF- $\mathrm{KB}$ is translocated into the nucleus (Kim et al., 2007; Li et al., 2015).
To investigate whether KSS-II phosphorylates both of these pathways, we used RAW 264.7 cells. To determine the optimal concentration range for KSS-II for treating RAW 264.7 cells, we measured the cell viability and selected concentrations from 1 to $25 \mu \mathrm{g} / \mathrm{mL}$ (data not shown). Resultantly, we found
(A)

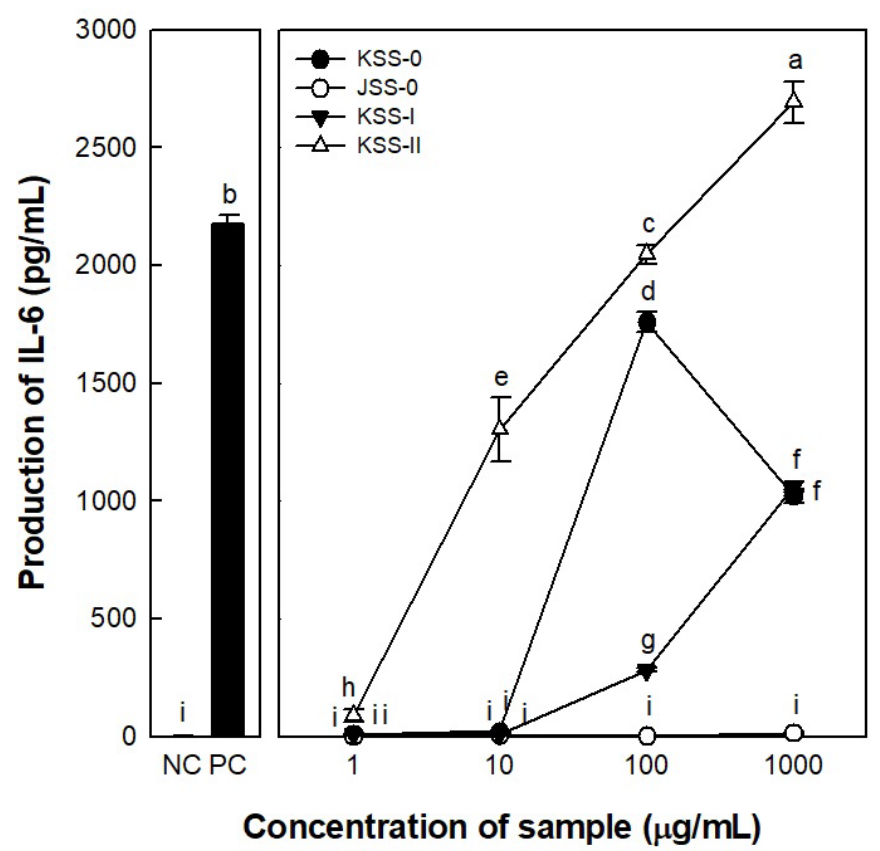

(C)

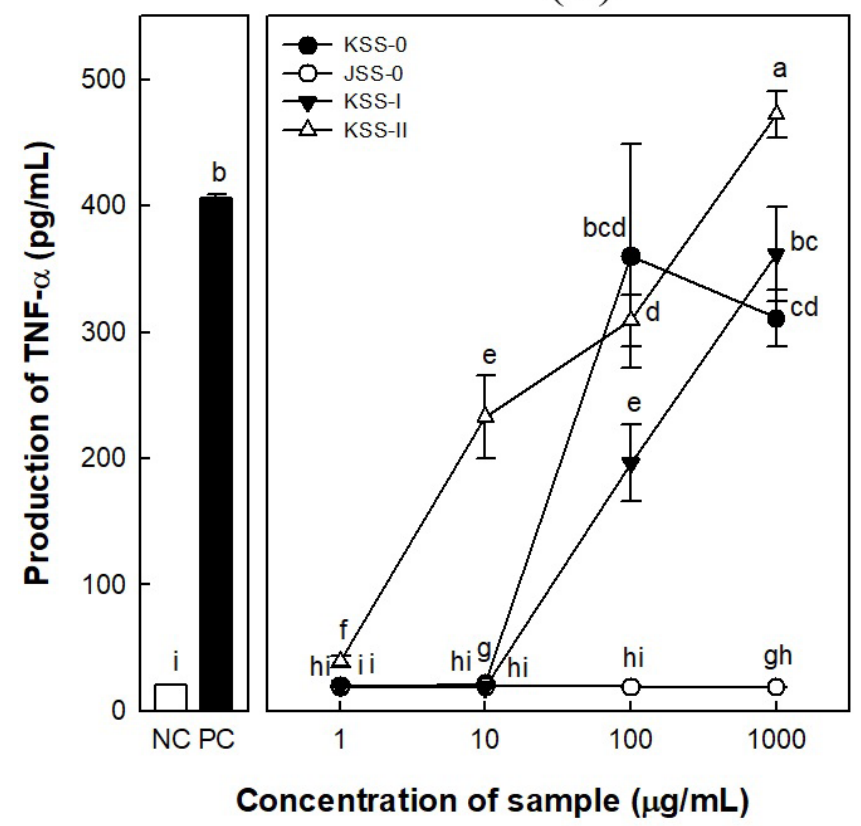

(B)

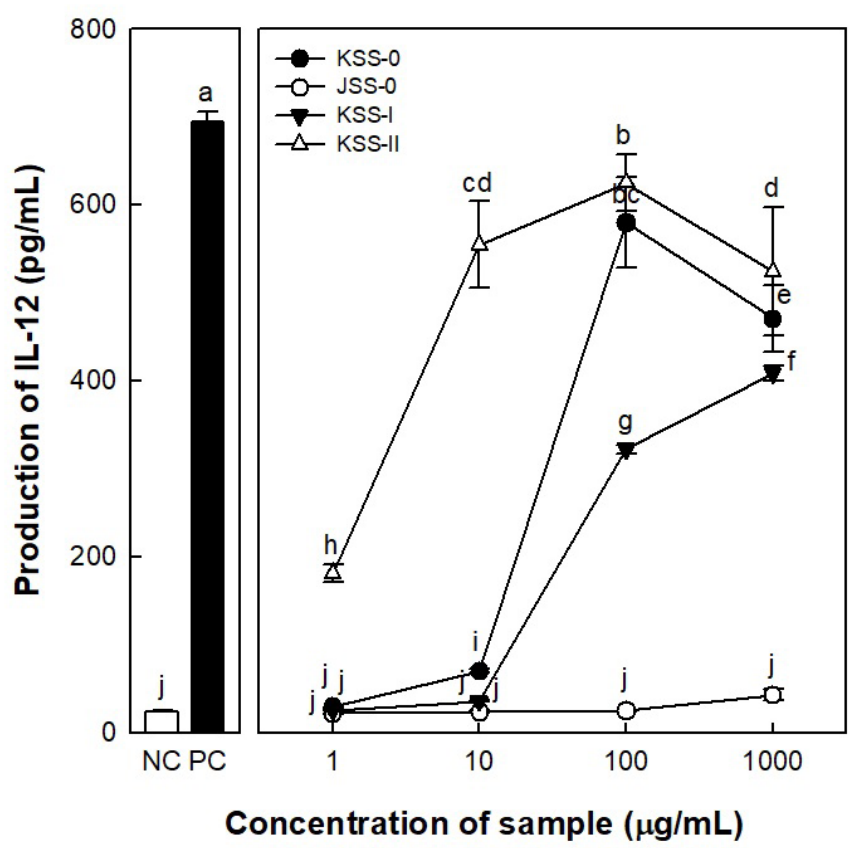

(D)

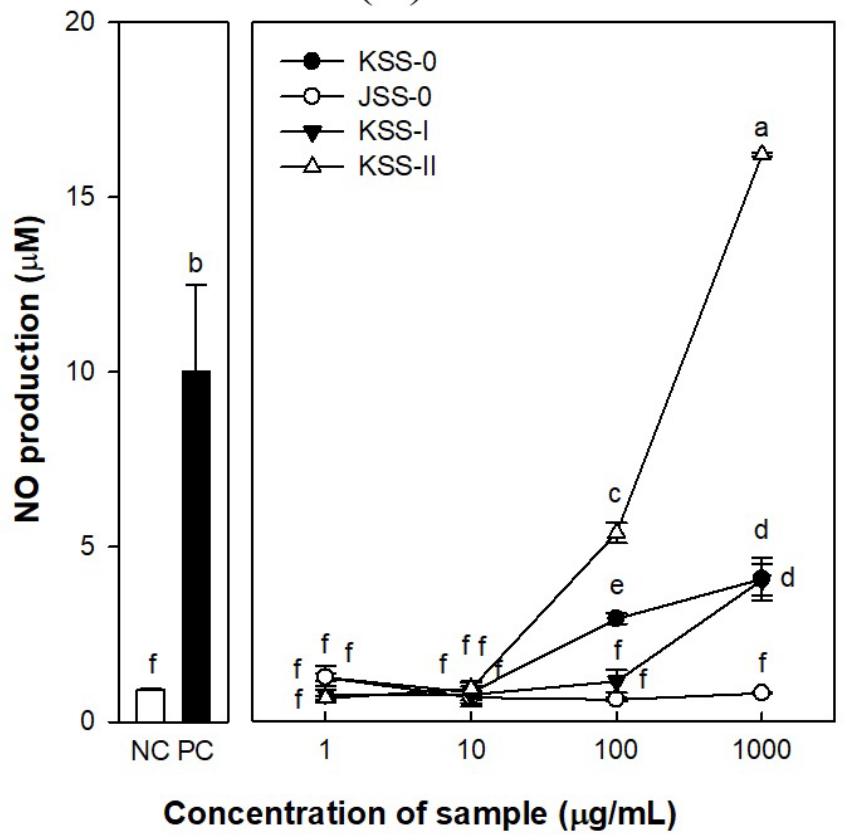

Figure 4. Effect of the four polysaccharides on cytokines and NO production. Peritoneal macrophages $\left(2.5 \times 10^{5} \mathrm{cells} / \mathrm{mL}\right) \mathrm{were}$ treated with polysaccharides for $24 \mathrm{~h}$. The level of protein was measured by ELISA (A-C). The level of NO was measured by Griess reagent (D). NC means negative control treated with media only. PC means the positive control treated with $1 \mu \mathrm{g} / \mathrm{mL}$ of LPS only. Data are presented as the mean \pm SD of three independent experiments. ${ }^{a-j}$ Values that do not share a common superscript vary significantly $(p<0.05)$ from each other. 


\section{$\operatorname{KSS}-\mathrm{II}(\mu \mathrm{g} / \mathrm{mL})$}

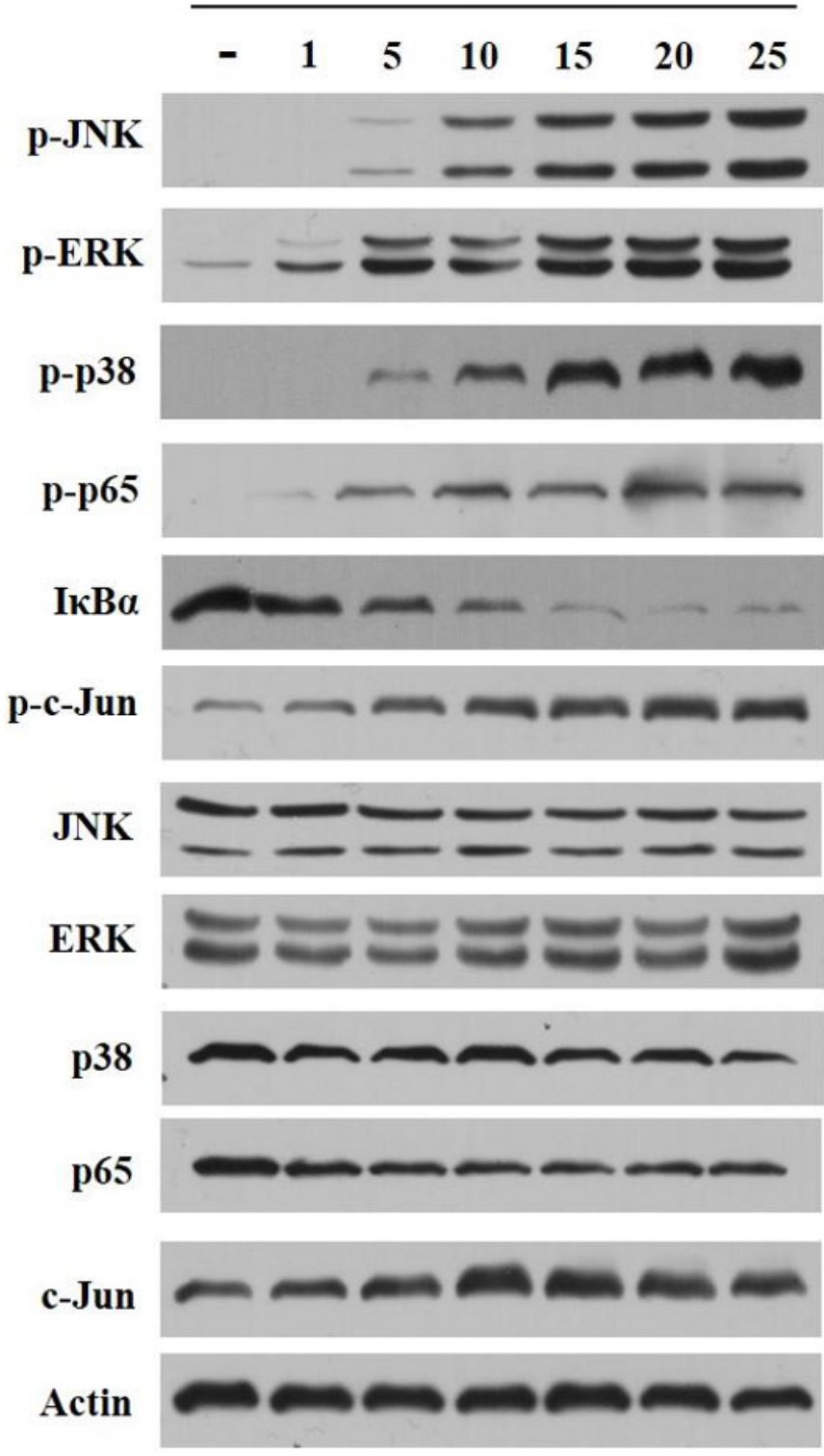

Figure 5. Phosphorylation of MAPKs, NF- $\kappa \mathrm{B}$ and $\mathrm{c}$-Jun in RAW 264.7 cells by KSS-II. RAW 264.7 cells $\left(2.5 \times 10^{6}\right.$ cells $\left./ \mathrm{mL}\right)$ were treated with KSS-II for $30 \mathrm{~min}$. Protein was extracted and immunoblotted with the indicated antibodies. $\beta$-actin was used as internal loading control.

that KSS-II significantly phosphorylated the MAPKs (p-JNK, p-ERK, and p-p38) and NF- $\mathrm{kB}$ (p-p65) in a concentrationdependent manner (Figure 5). c-Jun is a transcription factor and showed same result (p-c-Jun, Figure 5). Therefore, we believe that KSS-II activates macrophages via the MAPK and NF- $\kappa B$ pathways.

\section{Conclusions}

Soy sauce is a representative food in Korea, however, there are relatively limited studies on soy sauce in Korea compared to that in Japan. In this study, the immuno-stimulating activities are compared in polysaccharides isolated from soy sauce in Korea and Japan. Our results revealed that although there were no major differences in chemical composition of all the polysaccharides, KSS-II-treated cells showed highest production in NO and cytokines. Results of pathway analysis showed that KSS-II activates macrophages via MAPK and NF- $\kappa B$ pathways. Therefore, the polysaccharides isolated from Korean soy sauce have better immune-stimulating activities than its Japanese counterpart and might be potential candidates for functional foods.

\section{Acknowledgements}

This research was supported by Basic Science Research Program through the National Research Foundation of Korea (NRF) funded by the Ministry of Education (2017R1C1B5017634). The authors have no conflicts of interest to disclose.

\section{Reference}

Aderem, A., \& Underhill, D. M. (1999). Mechanisms of phagocytosis in macrophages. Annual Review of Immunology, 17(1), 593-623. http:// dx.doi.org/10.1146/annurev.immunol.17.1.593. PMid:10358769.

Billack, B. (2006). Macrophage activation: role of toll-like receptors, nitric oxide, and nuclear factor Kappa B. American Journal of Pharmaceutical Education, 70(5), 102. http://dx.doi.org/10.5688/ aj7005102. PMid:17149431.

Blumenkrantz, N., \& Asboe-Hansen, G. (1973). New method for quantitative determination of uronic acids. Analytical Biochemistry, 54(2), 484-489. http://dx.doi.org/10.1016/0003-2697(73)90377-1. PMid:4269305.

Chandarajoti, K., Xu, Y., Sparkenbaugh, E., Key, N. S., Pawlinski, R., \& Liu, J. (2014). De novo synthesis of a narrow size distribution low-molecular-weight heparin. Glycobiology, 24(5), 476-486. http:// dx.doi.org/10.1093/glycob/cwu016. PMid:24626379.

Diez-Simon, C., Eichelsheim, C., Mumm, R., \& Hall, R. D. (2020). Chemical and sensory characteristics of soy sauce: a review. Journal of Agricultural and Food Chemistry, 68(42), 11612-11630. http:// dx.doi.org/10.1021/acs.jafc.0c04274. PMid:32880168.

DuBois, M., Gilles, K. A., Hamilton, J. K., Rebers, P. A., \& Smith, F. (1956). Colorimetric method for determination of sugars and related substances. Analytical Chemistry, 28(3), 350-356. http://dx.doi. org/10.1021/ac60111a017.

Jia, X., Chen, M., Wan, J., Su, H., \& He, C. (2015). Review on the extraction, characterization and application of soybean polysaccharide. RSC Advances, 5(90), 73525-73534. http://dx.doi.org/10.1039/C5RA12421B.

Johnson, G. L., \& Lapadat, R. (2002). Mitogen-activated protein kinase pathways mediated by ERK, JNK, and p38 protein kinases. Science, 298(5600), 1911-1912. http://dx.doi.org/10.1126/science.1072682. PMid:12471242.

Jones, T. M., \& Albersheim, P. (1972). A gas chromatographic method for the determination of aldose and uronic acid constituents of plant cell wall polysaccharides. Plant Physiology, 49(6), 926-936. http:// dx.doi.org/10.1104/pp.49.6.926. PMid:16658086.

Kim, A., Kim, Y., Shim, J., \& Hwang, J. (2007). Immunostimulating activity of crude polysaccharide extract isolated from curcuma xanthorrhiza roxb. Bioscience, Biotechnology, and Biochemistry, 71(6), 1428-1438. http://dx.doi.org/10.1271/bbb.60241. PMid:17587672.

Kim, H. W., Shin, M., Lee, S. J., Park, H., Jee, H. S., Yoon, T. J., \& Shin, K. (2019). Signaling pathways associated with macrophage-activating polysaccharides purified from fermented barley. International 
Journal of Biological Macromolecules, 131, 1084-1091. http://dx.doi. org/10.1016/j.ijbiomac.2019.03.159. PMid:30914368.

Kim, H., Kwak, B., Hong, H., Suh, H., \& Shin, K. (2016). structural features of immunostimulatory polysaccharide purified from pectinase hydrolysate of barley leaf. International Journal of Biological Macromolecules, 87, 308-316. http://dx.doi.org/10.1016/j. ijbiomac.2016.02.072. PMid:26944661.

Kobayashi, M. (2005). Immunological functions of soy sauce: hypoallergenicity and antiallergic activity of soy sauce. Journal of Bioscience and Bioengineering, 100(2), 144-151. http://dx.doi. org/10.1263/jbb.100.144. PMid:16198255.

Kong, Y., Zhang, L., Zhang, Y., Sun, B., Sun, Y., Zhao, J., \& Chen, H. (2018). Evaluation of non-volatile taste components in commercial soy sauces. International Journal of Food Properties, 21(1), 1854-1866. http://dx.doi.org/10.1080/10942912.2018.1497061.

Lee, J., Ohta, Y., Hayashi, K., \& Hayashi, T. (2010). Immunostimulating effects of a sulfated galactan from codium Fragile. Carbohydrate Research, 345(10), 1452-1454. http://dx.doi.org/10.1016/j. carres.2010.02.026. PMid:20362278.

Li, L., Wang, L., Wu, Z., Yao, L., Wu, Y., Huang, L., Liu, K., Zhou, X., \& Gou, D. (2015). nthocyanin-rich fractions from red raspberries attenuate inflammation in both RAW264.7 macrophages and a mouse model of colitis. Scientific Reports, 4(1), 6234. http://dx.doi. org/10.1038/srep06234. PMid:25167935.

Liu, Y., Zhang, J., Tang, Q., Yang, Y., Guo, Q., Wang, Q., Wu, D., \& Cui, S. W. (2014). Physicochemical characterization of a high molecular weight Bioactive B-D-glucan from the fruiting bodies of ganoderma lucidum. Carbohydrate Polymers, 101, 968-974. http://dx.doi. org/10.1016/j.carbpol.2013.10.024. PMid:24299863.

Matsushita, H., Kobayashi, M., Tsukiyama, R., Fujimoto, M., Suzuki, M., Tsuji, K., \& Yamamoto, K. (2008). Stimulatory Effect of Shoyu Polysaccharides from Soy Sauce on the Intestinal Immune System. International Journal of Molecular Medicine, 22(2), 243-247. PMid:18636180.

Nie, L., Xiao, Q., Liu, S., Li, B., Duan, J., Fan, Y., Guo, L., He, C., \& Zhu, H. (2019). Immune-enhancing effects of polysaccharides MLN-1 from by-product of Mai-Luo-Ning in vivo and in vitro. Food and Agricultural Immunology, 30(1), 369-384. http://dx.doi.org/10.108 0/09540105.2019.1582612.

Park, H., Hwang, D., Suh, H., Yu, K., Kim, T. Y., \& Shin, K. (2017). Antitumor and antimetastatic activities of rhamnogalacturonanII-type polysaccharide isolated from mature leaves of green tea via activation of macrophages and natural killer cells. International Journal of Biological Macromolecules, 99, 179-186. http://dx.doi. org/10.1016/j.ijbiomac.2017.02.043. PMid:28223130.

Park, H., Lee, M., Jo, S., Won, H., Lee, H., Lee, H., \& Shin, K. (2012). Immuno-Stimulating Activities of Polysaccharides Isolated from Commercial Soy Sauce and Traditional Korean Soy Sauce. Korean Journal of Food Science Technology, 44(2), 228-234. http://dx.doi. org/10.9721/KJFST.2012.44.2.228.
Shin, M., Song, J. H., Choi, P., Lee, J. H., Kim, S., Shin, K., Ham, J., \& Kang, K. S. (2018). Stimulation of innate immune function by panax ginseng after heat processing. Journal of Agricultural and Food Chemistry, 66(18), 4652-4659. http://dx.doi.org/10.1021/acs. jafc.8b00152. PMid:29659255.

Tzianabos, A. O. (2000). Polysaccharide immunomodulators as therapeutic agents: structural aspects and biologic function. Clinical Microbiology Reviews, 13(4), 523-533. http://dx.doi.org/10.1128/ CMR.13.4.523. PMid:11023954.

Wang, H., Liu, Y. M., Qi, Z. M., Wang, S. Y., Liu, S. X., Li, X., Wang, H. J., \& Xia, X. C. (2013). An overview on natural polysaccharides with antioxidant properties. Current Medicinal Chemistry, 20(23), 2899-2913. http://dx.doi.org/10.2174/0929867311320230006. PMid:23627941.

Wang, Y., Cui, X., Tai, G., Ge, J., Li, N., Chen, F., Yu, F., \& Liu, Z. (2009). A critical role of activin a in maturation of mouse peritoneal macrophages in vitro and in vivo. Cellular \& Molecular Immunology, 6(5), 387-392. http://dx.doi.org/10.1038/cmi.2009.50. PMid:19887052.

Xing, Z., Zganiacz, A., \& Santosuosso, M. (2000). Role of IL-12 in macrophage activation during intracellular infection: IL-12 and mycobacteria synergistically release TNF- $\alpha$ and nitric oxide from macrophages via IFN- $\gamma$ induction. Journal of Leukocyte Biology, 68(6), 897-902. PMid:11129658.

Yang, A., Fan, H., Zhao, Y., Chen, X., Zhu, Z., Zha, X., Zhao, Y., Chai, X., Li, J., Tu, P., \& Hu, Z. (2019). An immune-stimulating proteoglycan from the medicinal mushroom huaier up-regulates nf-kb and mapk signaling via toll-like receptor 4. The Journal of Biological Chemistry, 294(8), 2628-2641. http://dx.doi.org/10.1074/jbc.RA118.005477. PMid:30602571.

Yang, Y., Kim, S. C., Yu, T., Yi, Y., Rhee, M. H., Sung, G., Yoo, B. C., \& Cho, J. Y. (2014). Functional roles of p38 mitogen-activated protein kinase in macrophage-mediated inflammatory responses. Mediators of Inflammation, 2014, 352371. http://dx.doi.org/10.1155/2014/352371. PMid:24771982.

Yoon, Y. D., Han, S. B., Kang, J. S., Lee, C. W., Park, S., Lee, H. S., Kang, J. S., \& Kim, H. M. (2003). Toll-like receptor 4-dependent activation of macrophages by polysaccharide isolated from the radix of platycodon grandiflorum. International Immunopharmacology, 3(13-14), 1873-1882. http://dx.doi.org/10.1016/j.intimp.2003.09.005. PMid:14636836.

Zhang, Z., Till, S., Jiang, C., Knappe, S., Reutterer, S., Scheiflinger, F., Szabo, C. M., \& Dockal, M. (2014). Structure-activity relationship of the pro-and anticoagulant effects of fucus vesiculosus fucoidan. Thrombosis and Haemostasis, 111(3), 429-437. PMid:24285223.

Zhao, J., Kiyohara, H., Yamada, H., Takemoto, N., \& Kawamura, H. (1991). Heterogeneity and characterisation of mitogenic and anticomplementary pectic polysaccharides from the roots of glycyrrhiza uralensis fisch et D.C. Carbohydrate Research, 219, 149-172. http:// dx.doi.org/10.1016/0008-6215(91)89049-L. PMid:1804531. 